\title{
INCIDÊNCIA DE DÍPTEROS MUSCÓIDES (INSECTA, DIPTERA) NO MUNÍCIPIO DE PRESIDENTE PRUDENTE, SP
}

\section{Leonice Seolin Dias ${ }^{1}$}

\author{
Tiago Viana Flor de Santana ${ }^{2}$
}

Raul Borges Guimarães ${ }^{3}$

Resumo: Realizou-se um estudo sobre a incidência de dípteros muscóides no Campus da UNESP de Presidente Prudente, São Paulo, no período da manhã e da tarde, de dezembro de 2009 a março de 2010. Os insetos foram capturados com seis armadilhas confeccionadas com garrafas tipo "pet", utilizando atrativos à base de fígado bovino e carcaças de peixe. No período da manhã as armadilhas foram colocadas às 6:00 horas e retiradas às 12:00 horas e no período da tarde houve troca das armadilhas e iscas às 12:00 horas, com retirada às 18:00 horas. Foi capturado um total de 235 moscas, sendo 35,31\% (83) no período da manhã e $64,69 \%$ (152) no da tarde. Desse total, $85,53 \%$ (201) pertenciam à família Calliphoridae, 9,36\% (22) à Sarcophagidae, 2,98\% (7) à Muscidae e 2,13\% (5) à Fanniidae. Os testes estatísticos não indicaram diferença significativa entre o número de moscas coletadas nos dois períodos estudados das famílias Calliphoridae e Sarcophagidae, considerando um nível de significância de $5 \%$. Possivelmente tal fato deve-se ao número reduzido de observações $(n=7)$ e a alta variabilidade dos dados, que podem ter acobertado um possível efeito. Os muscídeos e os fanideos foram pouco abundantes, apresentando frequência nula em muitas capturas, somaram juntos 12 espécimes coletados, de forma que não foi possível realizar a análise estatística com essas espécies. Os resultados deste trabalho levantam interessantes questões sobre a necessidade de se dar continuidade a estes estudos, tendo em vista a complexidade de se compreender o comportamento da flutuação das moscas em áreas urbanas.

\footnotetext{
${ }^{1}$ Doutoranda em Geografia, Universidade Estadual Paulista (UNESP), Presidente Prudente, SP. .(nseolin@gmail.com)

${ }^{2}$ Doutorando em Estatística, Universidade de São Paulo (USP) (tiagodesantana@yahoo.com.br)

${ }^{3}$ Professor adjunto do Departamento de Geografia da UNESP, Presidente Prudente, SP (raul@fct.unesp.br)
} 
Palavras-chave: Moscas sinantrópicas. Bioindicadores. Saúde ambiental.

\section{INTRODUÇÃO}

Ao converter o ambiente natural em área urbana, a ação do homem produz alterações profundas do ecossistema natural. Os efeitos da ação antrópica acabam extinguindo a maioria das espécies nativas e outras espécies são adaptadas ao ambiente degradado e perturbado, passando a beneficiar-se do material orgânico acumulado.

Destacamos que a excessiva produção de resíduos sólidos nas cidades é inevitável e ocorre diariamente em quantidades e diferenciadas composições que variam de acordo com o grau de desenvolvimento econômico, os diferentes níveis sociais e o tamanho da população, representando um dos graves problemas a ser enfrentado pelos administradores públicos.

Os resíduos sólidos, na zona urbana, produzidos pelas atividades humanas são representados, em sua grande maioria, por restos alimentares diversos provenientes do homem e animais e que com manejo inadequado e falta de tratamento, contribuem à organização de ecossistemas que possibilitam o aparecimento de criadouros de insetos, especialmente dípteros muscóides (moscas) que normalmente convivem com o homem.

Para Povolny (1971), são consideradas moscas sinantrópicas aquelas adaptadas às modificações ambientais produzidas pela ação humana. Elas, segundo Greenberg (1971) e Förster et al (2007), têm potencial de veiculação de mais de 100 microorganismos patôgenos, que estão associados a mais de 65 diferentes tipos de enfermidades humanas e animais, o que as tornam de grande importância médica e sanitária. Algumas espécies destes insetos são potenciais vetores de agentes etiológicos tais como bactérias, vírus, cistos de protozoários e ovos de helmintos (CHOW, 1940; GREENBERG, 1971).

Por outro lado, a qualidade ambiental de um determinado local pode ser avaliada pela presença de certas espécies de moscas e a sua abundância, tornando-as um indicador biológico. Paiva (1994) afirma que por se criarem no esterco, em carcaças e no lixo que apodrece, o aumento nas populações desses insetos são os indicadores de que esses resíduos necessitam de destinação adequada. 


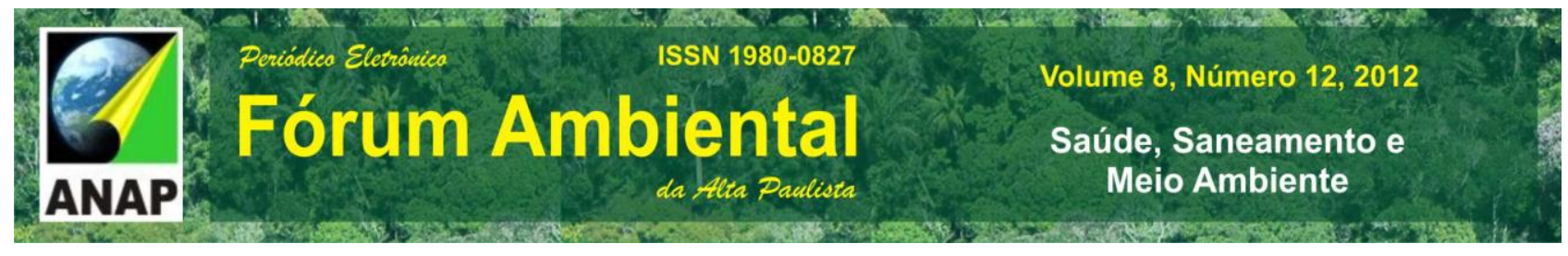

Ressaltamos que o estudo de animais tem sido uma das técnicas utilizadas para se avaliar mudanças no ambiente. Dentre os animais, os insetos são adequados para essa finalidade, tendo em vista sua diversidade e capacidade de produzir diversas gerações em curto espaço de tempo. Silveira Neto et al. (1995) defenderam a utilização desses organismos como indicadores ecológicos, por meio da análise faunística, como método de avaliar o impacto ambiental.

As moscas podem funcionar como indicadores de interferências humanas nos ambientes naturais por apresentarem rápida resposta populacional e sensibilidade ambiental. Essa sensibilidade em relação aos ambientes, aliada à rapidez de resposta em termos populacionais às modificações antrópicas, confere às moscas a capacidade de funcionarem como indicadores de interferências humanas nos ambientes naturais (MARTINS, 2001; ESPÓSITO; CARVALHO, 2006).

A flutuação e composição das populações de insetos em determinado ambiente podem ser influenciadas por fatores bióticos e abióticos. Teixeira et al. (2008), ressaltam que:

\begin{abstract}
... muitos fatores contribuem para a manutenção e o crescimento de populações de moscas sinantrópicas: as condições climáticas (temperatura e umidade elevadas), saneamento básico deficiente, acondicionamento inadequado de lixo, falta de conscientização da população e a dificuldade no controle destes insetos, agravada pela utilização indiscriminada de inseticidas. O controle de moscas sinantrópicas está relacionado às boas práticas de armazenagem e de produção de alimentos, ao adequado acondicionamento e destino final de resíduos sólidos bem como medidas preventivas capazes de reduzir a taxa de reprodução de insetos. Desta forma, o controle químico assume papel não prioritário sendo apenas mais uma ferramenta no controle integrado.
\end{abstract}

Dajoz (1983), também, ressalta que os fatores bióticos e abióticos são responsáveis pela ocorrência e variação nas abundâncias de moscas, mas conforme Vianna et al. (2004) os fatores climáticos são os mais relevantes no equilíbrio dessas populações.

\title{
OBJETIVO
}

A partir do exposto acima, este trabalho teve como objetivo avaliar a incidência de dípteros muscóides, nos meses de verão de 2009-2010, no período da manhã e da tarde, no campus da Universidade Estadual Paulista - UNESP de Presidente Prudente, SP. 


\section{MATERIAIS E MÉTODOS}

\section{Área de estudo}

O campus da UNESP ocupa uma área de aproximadamente 25 hectares, situado a cerca de um quilômetro do centro da cidade, na parte mais alta, e com expressiva cobertura arbórea, com predominância de plantas frutíferas como manga, goiaba, acerola, jabuticaba, dentre outras. Por esse ambiente circula diariamente um número significativo de pessoas (estudantes, funcionários e um público externo que participa das atividades de extensão ou utiliza de serviços prestados à comunidade). Essa população permanente e flutuante consome diversos tipos de alimentos e gera um volume de resíduos orgânicos, muitas vezes, mal acondicionados. Em vista disto, é preciso analisar a relação das condições ambientais da área de estudo e a presença de uma variedade de animais, aves e insetos, como é o caso das moscas. Desta forma, o estudo privilegia noções espaciais relacionadas com a ocorrência de moscas, e abre a perspectiva de se avançar na reflexão a respeito da contribuição da geografia para compreensão do comportamento desses insetos e da necessidade de seu monitoramento e controle para a melhoria da saúde ambiental (SEOLIN DIAS, FONSECA, GUIMARÃES, 2012).

\section{Captura das moscas}

Todos os insetos foram capturados, no período de dezembro de 2009 a março de 2010, no campus da UNESP de Presidente Prudente, São Paulo (Figura 1). 


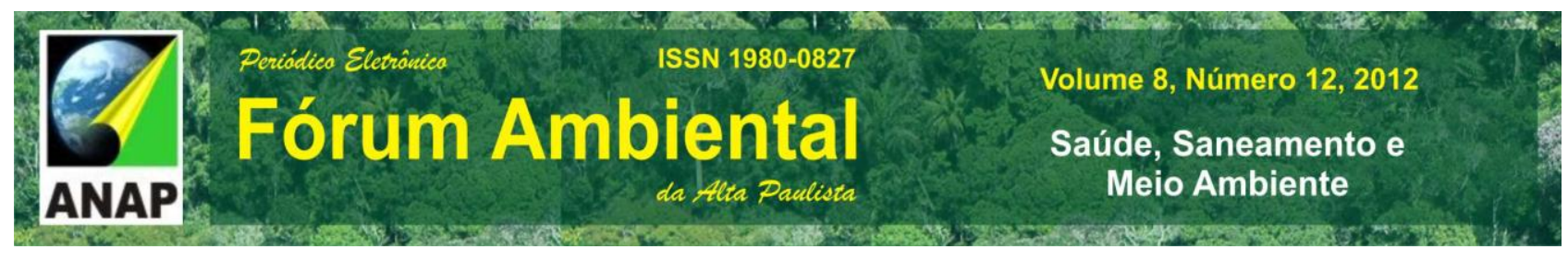

Campus da Universidade Estadual Paulista - Presidente Prudente, SP.

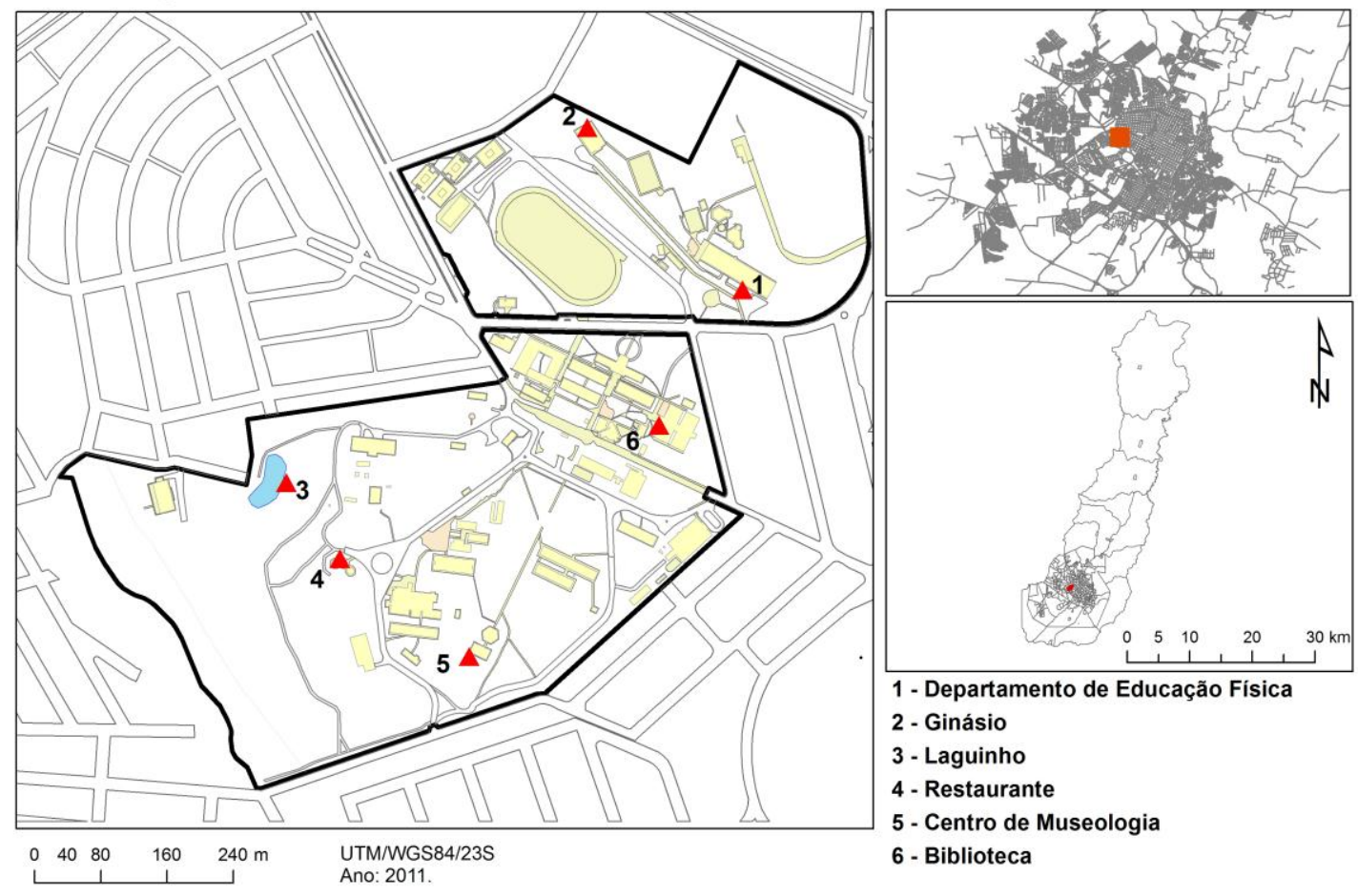

Figura 1. Pontos de captura de moscas no campus da Unesp, Presidente Prudente. Fonte: Meneguete et al. (2008). Org. Elivelton da Silva Fonseca (2012)

Adotou-se a época de verão para o desenvolvimento do experimento, uma vez que, segundo Knapp e Knutson (1958), no calor, pode ocorrer mais de uma geração de moscas por mês. Além disso, o inventário sobre a diversidade de moscas realizado por Seolin Dias (2008) no mesmo local do presente trabalho, revelou maior presença de califorídeos e muscídeos nos meses de verão.

Para a captura dos insetos, utilizou-se seis armadilhas confeccionadas com garrafas tipo "pet", de acordo com Ferreira (1978) e modificadas por Otsuka (2007). As armadilhas foram suspensas em árvores a uma altura de 1,0 a 1,50 m do solo, contendo aproximadamente $100 \mathrm{~g}$ de isca (fígado bovino e carcaça de peixe).

O monitoramento dos dípteros muscoídes ocorreu quinzenalmente, num total de 14 coletas, sendo sete no período da manhã e sete no período da tarde. No período da manhã, as armadilhas foram colocadas às 6:00 horas e retiradas às 12:00 horas e no período da tarde houve troca das armadilhas e iscas, às 12:00 horas, com retirada às 18:00 horas.

Após o período de exposição, as armadilhas com os insetos capturados foram transportadas ao Laboratório Geografia da Saúde da UNESP para a separação, contagem 
e identificação, por família de moscas (ALBUQUERQUE et al., 1981; CARVALHO; RIBEIRO, 2000; CARVALHO; COURI, 2002; CARVALHO; MOURA, RIBEIRO, 2002; MELLO, 2003; COURI; CARVALHO, 2005; CARVALHO; MELLO-PATIU, 2008).

Para comparação das capturas de moscas sinantrópicas entre os períodos manhã e tarde foi realizado o teste estatístico t de Student, para amostras pareadas, ao nível de 5\% de significância, com o auxílio do software estatístico R (R Core Team, 2012).

\section{RESULTADOS E DISCUSSÃo}

Durante o levantamento capturou-se 235 moscas, sendo 35,31\% (83 exemplares) no período da manhã e $64,69 \%$ (152), no período da tarde. Desse total, a família Calliphoridae representou 85,53\% (201), Sarcophagidae 9,36\% (22), Muscidae 2,98\% (7) e Fanniidae 2,13\% (5).

Observou-se que as temperaturas médias variaram de 20,0 a $32,30^{\circ} \mathrm{C}$, a umidade relativa média oscilou de 58,6 a 91,3\% e o índice de precipitação pluviométrica em 1,8 a $262,6 \mathrm{~mm}$, um total no período de $847,0 \mathrm{~mm}$.

Os califorídeos foram os mais frequentes com 71 insetos no período da manhã e 130 no da tarde, num total de 201. Sua maior ocorrência se deu na quarta coleta, com 52 espécimes, a temperaturas médias compreendidas entre 23,2 e $32,3^{\circ} \mathrm{C}$, umidade relativa 73,2 e 79,9\%, e índice de precipitação pluviométrica 109,2 mm. A menor abundância ocorreu na primeira captura com $3,98 \%$ (08) entre 21,7 a $31,6^{\circ} \mathrm{C}, 58,7$ a $84,9 \%$, e $41,8 \mathrm{~mm}$ (Figura 2). 


\section{Den

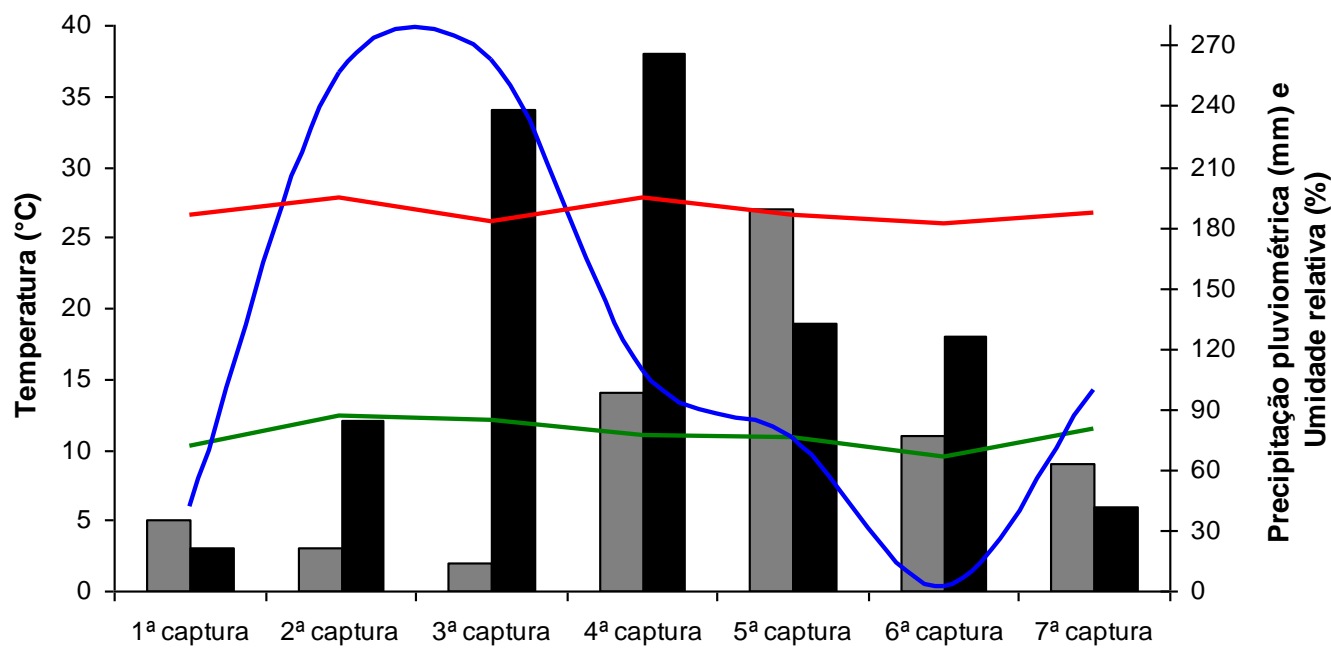

Califorídeos

Manhã $\square$ Tarde —Umidade Relativa(\%) — Precipitação $(\mathrm{mm})$ — Temperatura $\left({ }^{\circ} \mathrm{C}\right)$

Figura 2. Demonstrativo de califorídeos capturados, no período da manhã e da tarde, no período de dezembro de 2009 a março de 2010 , médias das temperaturas $\left({ }^{\circ} \mathrm{C}\right)$, umidade relativa do ar $(\%)$ e precipitação pluviométrica $(\mathrm{mm})$, no campus da UNESP, Presidente Prudente, SP.

Os califorídeos, popularmente conhecidos como moscas varejeiras, possuem grande importância em diferentes áreas. Segundo Guimarães e Papavero (1999), na área médica-veterinária, algumas espécies estão relacionadas com a ocorrência de míases no homem e em animais domésticos. Além disso, conforme Otsuka (2007) citando Ferreira (1978) e Fischer et al. (2004), estes insetos podem atuar como vetores passivos de microrganismos patogênicos para os seres humanos e entre animais. Larvas e adultos entram em contato com microrganismos, encontrados em secreções, excreções e tecidos infectados de animais, e podem se contaminar, transportando os microrganismos por alguns dias.

Destacamos que quatro espécies de moscas do gênero Chrysomya originárias do Velho Mundo e da África, foram introduzidas no Novo Mundo. No Brasil, pelo Estado do Paraná, na década de 1970, foram as espécies Chrysomya megacephala, C. rufifacies, $C$. albiceps e C. putoria Esses dípteros apresentam um alto potencial de adaptação e colonização de novos ambientes, o que resultou na redução significativa das populações de moscas nativas e na sua rápida dispersão por todo o território nacional (GUIMARÃES et al., 1979; GUIMARÃES; PAPAVERO, 1999). 
Os califorídeos podem ser atraídos por substâncias em processo de fermentação, decomposição, sangue e feridas (GAULD; BOLTON, 1988) e são encontrados em abatedouros, estábulos de gado leiteiro, frigoríficos, aviários, plantas em decomposição, lixo doméstico feiras livres, curtumes, aterros sanitários e lixão a céu aberto, e em frutos caídos (BORROR; DELONG, 1988).

A família Sarcophagidae foi a segunda de maior incidência, com um total de 22 exemplares, sendo cinco no período da manhã e 17 no da tarde. Foram mais abundantes na sexta coleta, com sete espécimes (um indivíduo no período da manhã e seis no da tarde), a 20,8 e $31,2^{\circ} \mathrm{C}, 60,9$ e $70,9 \%$ e $1,8 \mathrm{~mm}$. A menor frequência foi observada na sétima coleta, no período da tarde, com um exemplar, a 21,8 e $31,4^{\circ} \mathrm{C}, 77,3$ e $84,0 \%$, e $99,1 \mathrm{~mm}$. Não houve captura na primeira coleta entre 21,7 a $31,5^{\circ} \mathrm{C}, 58,6$ a $84,8 \%$, e $41,8 \mathrm{~mm}$ (Figura 3 ).

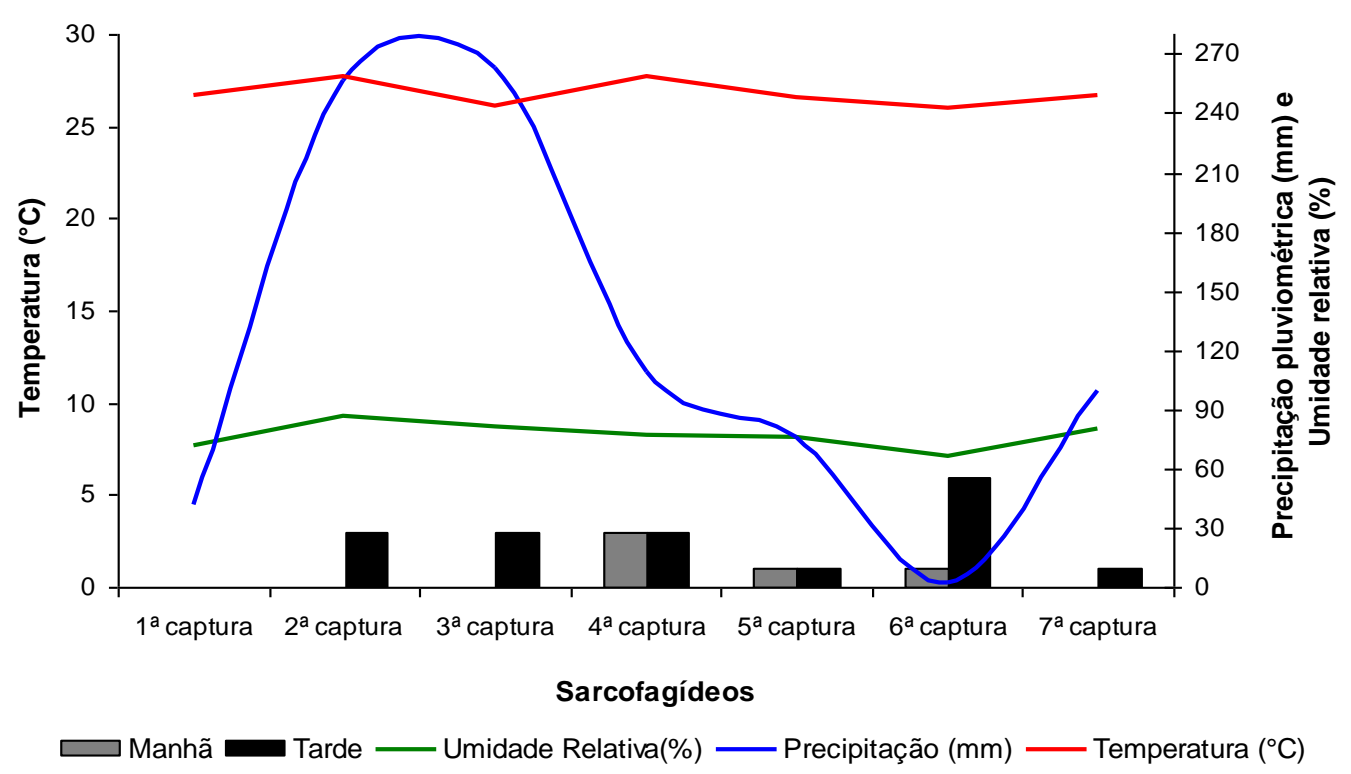

Figura 3. Demonstrativo de sarcofagideos capturados, no período da manhã e da tarde, no período de dezembro de 2009 a março de 2010, médias das temperaturas $\left({ }^{\circ} \mathrm{C}\right)$, umidade relativa do ar (\%) e precipitação pluviométrica $(\mathrm{mm})$, no campus da UNESP, Presidente Prudente, SP.

Os sarcofagídeos são de grande interesse médico sanitário. Sua ocorrência, distribuição e predominância nas áreas metropolitanas são fatores de grande importância. Sua presença já foi observada em cadáveres humanos e de animais domésticos. Os 
insetos adultos podem ser atraídos por substâncias em processo de fermentação, decomposição, sangue e feridas (GREENBERG, 1971; MARCHENKO, 1985).

Os membros das famílias Muscidae e Fanniidae foram pouco abundantes nas capturas, somaram juntos 12 espécimes do total coletado. Dessa forma, optou-se por não representar graficamente a amostra encontrada, mas apenas descrevê-la.

Os muscídeos ocuparam a terceira posição, com 2,98\% (07) exemplares, com um inseto na primeira captura, no período da tarde, a 21,72 a $31,55^{\circ} \mathrm{C}, 58,6$ a $84,8 \%$, e $41,8 \mathrm{~mm}$; e, na terceira, com seis moscas (05 no período da manhã e 01 no da tarde) a 21,9 a $30,1^{\circ} \mathrm{C}, 72,1$ a $91,2 \%$, e $262,6 \mathrm{~mm}$. Nas demais capturas não foram registradas a presença desses dípteros.

Apesar de ter havido pouco registro, algumas espécies de muscídeos são de grande importância médico sanitária, a exemplo da espécie Musca domestica que é uma mosca não-hematófaga, cosmopolita, de alto poder reprodutivo, que prolifera em vários tipos de substratos, tantos no meio urbano quanto no meio rural. Além disso, é um dos insetos mais amplamente distribuídos no mundo e mais frequentemente associado ao homem (WEST, 1951; OMS, 1986). Alimentam-se de substâncias líquidas ou que se liquefazem: fezes, escarro, pus, exsudato de feridas, produtos animais e vegetais em decomposição entre outros. As substâncias líquidas são diretamente ingeridas, ao passo que as sólidas são dissolvidas pela saliva e um líquido regurgitado do tubo digestivo (PAIVA, 1994).

Já os fanídeos ocuparam a quarta posição, com 2,13\% (05) indivíduos capturados, sendo dois no período da tarde, na segunda coleta, a 22,7 a $30,7^{\circ} \mathrm{C}, 79,3$ a $93,1 \%$, e $256,3 \mathrm{~mm}$; dois na terceira (01 no período da manhã e 01 no da tarde) a 21,9 a $30,1^{\circ} \mathrm{C}, 77,0$ a $91,2 \%$ e e $262,6 \mathrm{~mm}$ e um inseto na quarta, no período da manhã, a 23,1 a $32,3^{\circ} \mathrm{C}, 73,1$ a $79,9 \%$ e 109,2 mm. Não houve coleta dessas moscas nas demais capturas.

De acordo com Couri e Carvalho (2005), os fanídeos são encontrados em todas as regiões zoogeográficas do mundo, com a maioria dos adultos frequentando áreas de florestas. Os machos dessa família apresentam o comportamento de ficar pairando no ar à espera de alimento, enquanto que as fêmeas geralmente são encontradas na vegetação e em detritos orgânicos no solo. A espécie Fannia pusio dessa família desenvolve-se em quase todos os tipos de matéria orgânica animal e vegetal em decomposição e também em fezes; algumas se criam em fungos, outras em ninhos de pássaros e tocas de mamíferos. 
Para comparação das capturas de moscas sinantrópicas entre os períodos manhã e tarde foi realizado o teste estatístico t de Student, para amostras pareadas, fixando nível de $5 \%$ de significância, com o auxílio do software estatístico $R$ ( $R$ Core Team, 2012). Devido à baixa frequência e até mesmo a frequência nula de muscideos e fanideos em muitas capturas, os testes estatísticos não foram realizados para essas famílias.

$\mathrm{O}$ teste $\mathrm{t}$ de Student não indicou diferença significativa $(\mathrm{t}=1,8298, \mathrm{p}=$ 0,1170 ), entre as populações de moscas capturadas nos períodos da manhã e da tarde, de forma que não se pode afirmar que o maior índice de predominância no período da tarde, com valor médio de 21,71 moscas coletadas; e, no período manhã 11,85 , se deve à influência do período.

Do mesmo modo, com relação às famílias Calliphoridae e Sarcophagidae, não houve diferença estatística significativa, ao nível de $5 \%$, entre o número de moscas das duas famílias capturadas nos períodos da manhã e da tarde. O maior número médio de Calliphorideos foi observado no período da tarde 18,57; e, no período da manhã 10,14 ( $\mathrm{t}=$ $1,5094 ; p=0,1819)$. O maior número médio de Sarcophagideos também foi registrado no período da tarde 2,42 e, no período da manhã 0,71 ( $t=-2,2953 ; p=0,0615$ ). Possivelmente a diferença na coleta de insetos destas duas famílias entre os períodos é atribuída à variabilidade natural não controlada do experimento.

Por outro lado, o número reduzido de observações $(n=7)$ e a alta variabilidade dos dados, Tabela 1, podem ter acobertado um possível efeito do período e influenciado nos resultados das análises estatísticas.

Tabela 1. Estatísticas descritivas: Medidas de dispersão dos dados.

\begin{tabular}{lcccc}
\hline & Média & Variância & Desvio Padrão & Coeficiente de variação (\%) \\
\hline Moscas & 33,57 & 356,28 & 18,87 & 56,22 \\
Calliphoridae & 28,71 & 283,23 & 16,82 & 58,61 \\
Fannidae & 0,71 & 0,90 & 0,95 & 133,16 \\
Muscidae & 1,00 & 5,00 & 2,23 & 223,60 \\
Sarcophagidae & 3,14 & 6,47 & 2,54 & 80,97 \\
\hline
\end{tabular}




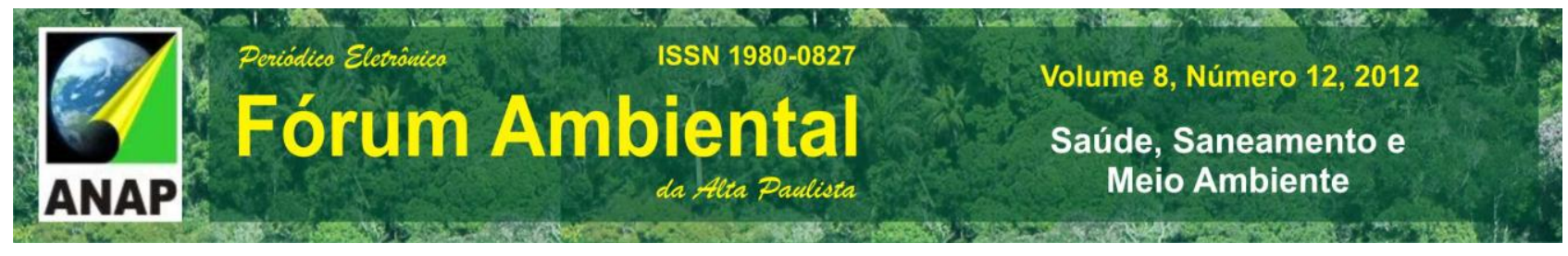

Estudos posteriores serão necessários para se compreender melhor a dinâmica de populações de moscas, nas demais estações do ano, no período da manhã e da tarde, uma vez que este trabalho apresenta coletas realizadas somente na estação de verão.

Até o presente momento não foram verificados outros trabalhos sobre a flutuação de moscas, no período da manhã e da tarde, no verão, em Campus universitário, o que impossibilita o processo de análise comparativa do presente estudo.

\section{CONCLUSÕES}

Os califorídeos destacaram-se nos dois períodos de estudo, devido sua relativa abundância e ocorrência. Possivelmente, isto ocorreu em virtude da ação antrópica, o que resulta em maior oferta de substratos para alimentação e proliferação.

Não houve diferença significativa entre o número de moscas coletadas nos dois períodos estudados das famílias Calliphoridae e Sarcophagidae, considerando um nível de significância de $5 \%$.

Os membros das famílias Muscidae e Fanniidae foram pouco abundantes nas capturas; somaram juntos 12 espécimes do total coletado.

Observou-se da amostra estudada que a maior presença de dípteros muscóides, nos meses de verão, ocorreu no período vespertino, entretanto os testes estatísticos não indicaram influência significativa do período. Possivelmente tal fato seja devido ao número reduzido de observações $(n=7)$ e a alta variabilidade dos dados, que podem ter acobertado um possível efeito do período e influenciado nos resultados das análises estatísticas, sendo necessários estudos mais aprofundados sobre número de observações, ideal para a estabilização da variabilidade dos dados e/ou possível análises estatísticas alternativas.

Os resultados do presente trabalho levantam interessantes questões sobre a necessidade de se dar continuidade a estes estudos, tendo em vista a complexidade de se compreender o comportamento da flutuação das moscas em áreas urbanas para minimizar os riscos de transmissão de agentes patogênicos por esses insetos. 


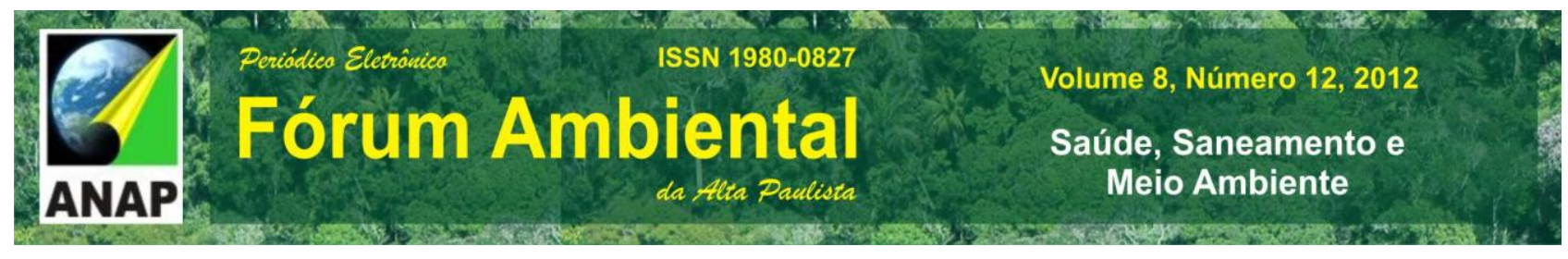

\section{REFERÊNCIAS}

ALBUQUERQUE, D. DE O.; PAMPLONA, D.; CARVALHO, C. J. B. Contribuição ao conhecimento dos Fannia R.-D., 1830 da Região Neotropical (Diptera, Fanniidae). Arquivos do Museu Nacional, v. 56, p. 9-34, 1981.

BORROR, D. J.; DELONG, D. M. Introdução ao estudo dos insetos. São Paulo: Editora Edgard Blucher Ltda, 1988, $635 \mathrm{p}$.

CARVALHO, C. J. B.; RIBEIRO, P. B. Chave de identificação das espécies de calliphoridae (Diptera) do sul do Brasil. Revista Brasileira de Parasitologia Veterinária, v. 9, p. 169-173, 2000.

CARVALHO, C. J. B.; COURI, M. S. Part I. Basal Groups. In: CARVALHO, C. J. B. org. Muscidae (Diptera) of the neotropical region - taxonomy. Curitiba, UFPR. p.17-126, 2002.

CARVALHO, C. J. B.; MOURA, O. M.; RIBEIRO, P. B. Chave para adultos de dípteros (Muscidae, Fannidae, Anthomyiidae) associados ao ambiente humano no Brasil. Revista Brasileira de Entomologia, v. 46, n. 2; p. 107-114, 2002.

CARVALHO, C. J. B.; MELLO-PATIU, C. A. Key to the adults of the most common forensic species of Diptera in South America. Revista Brasileira de Entomologia, v. 52, n. 3, p. 390-406, 2008.

COURI, M. S.; CARVALHO, C. J. B. Díptera Muscidae do estado do Rio de Janeiro (Brasil). Biota Neotropica, Campinas, v. 5, n. 2, p. 205-222, 2005.

COURI, M. S.; CARVALHO, C. J. B. Part II. Apical groups, p. 133-287. In: C.J.B. de. Carvalho (ed.). Muscidae (Diptera) of the Neotropical Region: Taxonomy. Curitiba: Editora Universidade Federal do Paraná, 2002.

CHOW, C. Y. The common blue bottle fly Chrysomya megacephala as a carrier of pathogenic bacteria in Peiping. China. Chinese Medical, v. 57, p. 145-153, 1940.

DAJOZ, R. Ecologia Geral. 4 ed. Petrópolis: Vozes, 1983. 472 p.

ESPOSITO, M.C.; CARVALHO, F. S. Composição e abundância de califorídeos e mesembrinelídeos (Insecta, Díptera) nas clareiras e matas da base de extração petrolífera, Bacia do Rio Urucu, Coari, Amazonas. In: II Workshop de Avaliação Técnica e Científica, Manaus, 2002.

GREENBERG, Bernard. Flies and diseases. Ecology, classification and biotic associations. Princeton: Princeton University, 1971. 856 p.

GUIMARÃES, J. H.; PAPAVERO, N. Myiasis in man and animals in the Neotropical region. Plêiade/FAPESP, São Paulo, 1999. 


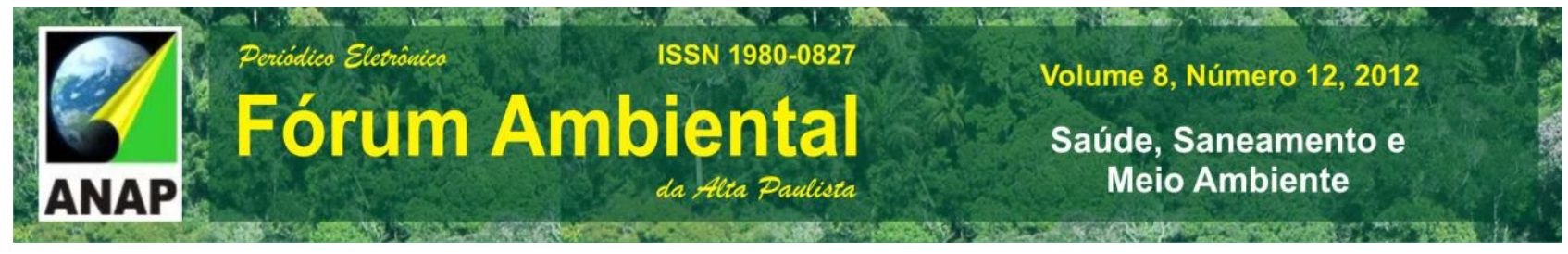

GUIMARAES; J. H.; PRADO, A. P.; BURALLI, G. M. Dispersal and distribution of three newly introduced species of Chrysomya Robineau-Desvoidy in Brazil (Díptera - Calliphoridae). Revista Brasileira de Entomologia, v. 23, p.245-255, 1979.

GAULD, I. D.; BOLTON, B. The Hymenoptera. Oxford: Oxford University Press, 1988, 331 p.

FÖRSTER, M.; S. SLIMPEL, S.; MEHLHORN, H.; K. SIEVERT. K.; MESSLER. S.; FEFFER, K. Pilot study on synanthropic flies (e.g. Musca, Sarcophaga, Calliphora, Fannia, Lucilia, Stomoxys) as vectors of pathogenic microorganisms. Parasitol. Parasitology Research, v.101, n.1, p. 243246, 2007.

FERREIRA, M. J. M. Sinantropia de dípteros muscóideos de Curitiba, Paraná. I. Calliphoridae. Revista Brasileira de Biologia, v. 38, p. 445-454, 1978.

KNAPP, F. W.; KNUTSON, H. Reproductive potential and longevity of two relatively isolated field populations of insecticide-susceptible house flies. Journal of Economic Entomology , v.51, p.4345, 1958.

MARCHENKO, M. I. Characteristic of development of the fly Chrysomya albiceps (Wd.) (Diptera, Calliphoridae). Entomology Obozr,. v. 64: 79-84, 1985.

MARTINS, M. B. Guilds of Drosophilids on Forest Fragments. In: R.O. Bierregaard; C. Gascon; T.E. Lovejoy. (Org.). Lessons from Amazonia. The ecology and conservation of a fragmented forest. Yale: yale University, 2001.

MELLO, R. P. de. 2003. Chave para a identificação das formas adultas das espécies da família Calliphoridae (Diptera, Brachycera, Cyclorrhapha) encontradas no Brasil. Entomologia y Vectores, v. 10, p. 255-268, 2003.

OTSUKA, $\mathrm{H}$. Sinantropia e sazonalidade de moscas varejeiras (Diptera: Calliphoridae) no sudeste do Brasil: visões ecológica, médica, veterinária e forense. 39 f. 2007. Monografia (Ciências Biológicas). Departamento de Parasitologia do Instituto de Biociências - UNESP _ Câmpus de Botucatu.

OMS. ORGANIZAÇÃO MUNDIAL DA SAÚDE. Resistance aux pesticides des vecteurs et réservoirs de maladies. Ginebra: OMS, 1986, p. 811 (Serie de Informes Técnicos, n.737).

PAIVA, D. P. As moscas como indicadores biológicos da alteração ambiental Concórdia, SC. Disponível em: < http://www.cnpsa.embrapa.br/pnma/pdf_doc/6-Dora-moscas.pdf> Acesso em: 28 set. 2012.

POVOLNÝ, David. Synanthropy flies and disease, Ecology, classification, and biotic associations. Princeton Univ. Press.Princeton. N. J., 1971, p. 17-54.

POVOLNY, D. (1971) Synanthropy. Flies and diseases vol. I: Ecology, classification and biotic associations (ed. by Greenberg, B.), pp. 16-45. Princeton University Press, Princeton.

R Core Team (2012). R: A language and environment for statistical computing. R Foundation for Statistical Computing, Vienna, Austria. ISBN 3-900051-07-0, URL http://www.R-project.org/. 
SEOLIN DIAS, L. Biodiversidade de moscas Calliphoridae e Muscidae no depósito de lixo urbano de Presidente Prudente, São Paulo, Brasil. 2008. 40 f. Dissertação (Mestrado em Ciência Animal). Universidade do Oeste Paulista, Presidente Prudente, SP.

SEOLIN DIAS, L.; FONSECA, E. S.; GUIMARÃES, R. B. Distribuição espacial de moscas sinantrópicas (Insecta, Díptera) no Campus da UNESP de Presidente Prudente (SP). Revista Geoatos, n. 12, v.1, p.43-53, 2012.

SILVEIRA NETO, S.; MONTEIRO, R. C.; ZUCCHI, R. A.; MORAES, R. C. B. 1995. Uso de análise faunística de insetos na avaliação do impacto ambiental. Scientia agrícola, v. 52, p. 9-15, 1995.

TEIXEIRA, A. F. M. et al. Controle de mosca doméstica em área de disposição de resíduos sólidos no Brasil. Engenharia Sanitaria Ambiental, v.13, n.4, 2008.

VIANNA, E. E. S.; COSTA, P. R. P.; FERNANDES, A. L; RIBEIRO, P.B. Abundância e flutuação populacional das espécies de Chrysomya (Díptera, Calliphoridae) em Pelotas, Rio Grande do Sul, Brasil. Iheringia, Série Zoologia, v.94, p.231-234, 2004.

WEST, L. S. The Housefly, its Natural History, Medical Importance, and Control. Comstock Publ Co. Ithaca, N.Y, 1951. 584 p. 